\title{
PENGARUH TERAPI FARMAKOLOGI DAN NON- FARMAKOLOGI TERHADAP PENURUNAN NYERI MENSTRUASI PADA MAHASISWI FAKULTAS FARMASI UNIVERSITAS BHAKTI KENCANA BANDUNG
}

\author{
Ani Anggriani ${ }^{1}$, Yani Mulyani ${ }^{2}$, Lili Dinda Pratiwi ${ }^{3}$ \\ ${ }^{1234}$ Universitas Bhakti Kencana \\ Email korespondensi: ani.anggriani@bku.ac.id
}

\begin{abstract}
ABSTRAK
Nyeri menstruasi (dismenore) adalah nyeri pada sebelum atau saat berlangsungnya menstruasi di bagian bawah perut akibat kram rahim. Prevalensi terjadinya dismenore di indonesia yaitu 54\% dismenore primer dan 9\% dismenore sekunder. Karena nyeri hebat yang dirasakan saat menstruasi $10 \%$ remaja putri mengalami absen sekolah dan kerja selama 3 hari setiap bulannya. Penelitian ini bertujuan untuk mengetahui pengaruh terapi farmakologi dan non-farmakologi terhadap penurunan nyeri menstruasi pada remaja. Penelitian ini merupakan penelitian eksperimental dengan rancangan one group pretest-post test. Sampel penelitian menggunakan metode purposive sampling, dengan sampel berjumlah 76 responden. Data dianalisis menggunakan uji Wilcoxon Signed Rank Test \& uji chi-square. Hasil penelitian diketahui bahwa uji Wilcoxon dengan hasil Sig. 0,000<0.05, artinya ada perbedaan intensitas nyeri menstruasi saat sebelum \& sesudah terapi, sehingga dapat disimpulkan bahwa ada pengaruh terapi farmakologi dan non-farmakologi terhadap penurunan intensitas nyeri menstruasi. Untuk hubungan terapi non-farmakologi hasil uji Chi-Square memiliki nilai Sig. 0,514>0,05, artinya tidak ada hubungan yang signifikan terhadap intensitas nyeri menstruasi. Untuk hubungan terapi farmakologi memiliki hasil Sig. $0,019<0,05$, artinya ada hubungan yang signifikan terhadap intensitas nyeri menstruasi pada remaja putri di Universitas Bhakti Kencana Bandung.
\end{abstract}

Kata kunci : Farmakologi, Non-Farmakologi, Nyeri Menstruasi 


\title{
THE EFFECT OF PHARMACOLOGICAL AND NON- PHARMACOLOGICAL THERAPY ON THE REDUCTION OF MENSTRUAL PAIN IN STUDENTS OF THE FACULTY OF PHARMACY, BHAKTI KENCANA UNIVERSITY, BANDUNG
}

\begin{abstract}
Menstrual pain is a problem that women often complain about in their teens. Menstrual pain (dysmenorrhea) is pain before or during menstruation in the lower abdomen due to uterine cramps. The prevalence of dysmenorrhea in Indonesia is 54\% primary dysmenorrhea and 9\% secondary dysmenorrhea. Due to the severe pain that is felt during menstruation, 10\% of teenage girls are absent from school and work for 3 days each month. This study aims to determine the effect of pharmacological \& nonpharmacological therapy on reducing menstrual pain in adolescents. This research is an experimental research with one group pretest-post test design. The research sample used purposive sampling method, with a sample of 76 respondents. Data were analyzed using the Wilcoxon Signed Rank Test \& chi-square test. The results showed that the Wilcoxon test with the results of Sig. $0.000<0.05$, meaning that there is a difference in the intensity of menstrual pain before \& after therapy. So it can be concluded that there is an effect of pharmacological and non-pharmacological therapy on decreasing the intensity of menstrual pain. For the relationship of non-pharmacological therapy Chi-Square test results have a value of Sig. 0.514>0.05, meaning that there is no significant relationship to the intensity of menstrual pain. For the relationship between pharmacological therapy, the results of Sig. $0.019<0.05$, meaning that there is a significant relationship with the intensity of menstrual pain in adolescent girls at Bhakti Kencana University, Bandung.
\end{abstract}

Keywords : Pharmacology, Non-Pharmacology, Menstrual pain

\section{PENDAHULUAN}

Dismenore atau nyeri menstruasi adalah masalah yang sering dikeluhkan oleh perempuan. Menstruasi adalah perdarahan yang tarjadi dari uterus bersamaan dengan serpihan selaput dinding uterus pada wanita yang terjadi

https://doi.org/10.33759/jrki.v3i3.156 
secara periodik dan siklus (Ayu et al., 2015). Dismenore memiliki dua kategori, yaitu dismenore primer menyebabkan nyeri ringan sampai sedang di bagian bawah pusar, diikuti dengan rasa sakit di bagian punggung, pinggang, paha dan kepala dan dismenore sekunder penyebab nyerinya dapat diketahui dalam 8-72 jam ketika menstruasi (Widowati et al.,2020).

Dari beberapa laporan internasional 50\% remaja putri mengalami dismenore di sepanjang tahun. Hasil studi terbaru melaporkan $10 \%$ remaja putri yang mengalami absen sekolah dan absen kerja selama \pm 3 hari setiap bulannya. Prevalensi terjadinya dismenore di indonesia yaitu $54,89 \%$ dismenore primer dan 9,38\% dismenore sekunder (Asmita dahlan, 2016). Dismenore primer lebih banyak terjadi di indonesia dan sangat menggangu konsentrasi juga aktivitas perempuan di indonesia. Nyeri menstruasi yang ditimbulkan dari dismenore juga sangat tidak nyaman, sehingga menyebabkan mudah marah dan gampang tersinggung.

Upaya untuk meredakan rasa nyeri dapat dilakukan dengan dua terapi atau cara pengobatan. Pengobatan pertama yaitu dengan pengobatan farmakologi, yang dapat dilakukan dengan menggunakan obat-obatan penghilang rasa nyeri (analgesik). Yang kedua dengan pengobatan non-farmakologi dapat dilakukan dengan berolahraga, kompres hangat atau dingin, terapi musik, relaksasi dan mengkonsumsi jamu atau minuman herbal (Widowati et al., 2020)

Berdasarkan uraian diatas maka perlu dilakukan penelitian pengaruh terapi farmakologi dan terapi non-farmakologi terhadap penurunan nyeri menstruasi. Penelitian ini bertujuan untuk mengetahui pengaruh terapi farmakologi dan non-farmakologi terhadap penurunan nyeri menstruasi. Mahasiswa di Universitas Bhakti Kencana Bandung dipilih menjadi subjek penelitian karena mayoritas mahasiswa berjenis kelamin perempuan.

\section{METODE PENELITIAN MATERIAL}

Penelitian ini merupakan penelitian eksperimental dengan rancangan one group pretest-post test tanpa kelompok pembanding. Pengaruh perlakukan akan dilihat dari nilai yang didapatkan dari nilai pretest dan nilai post test. Penelitian dirancang untuk mengungkapkan hubungan sebab akibat, dimana peneliti akan melakukan https://doi.org/10.33759/jrki.v3i3.156 
observasi sebelum perlakukan dan dilakukan observasi kembali setelah diberi perlakuan (Fitri Maulani et al., 2018). Purposive sampling merupakan metode yang digunakan dalam pengumpulan sampel dari populasi dengan kriteria yang diinginkan, sehingga sampel yang didapat memenuhi karakteristik (Lestari et al., 2019). Pemberian terapi farmakologi dari jenis obat analgesik golongan obat antiinflamasi non steroid (OAINS) dan non-farmakologi seperti kompres hangat, kompres dingin, abdominal stretching, dan mengkonsumsi produk minuman herbal digunakan sebagai variabel independen. Sedangkan penurunan intensitas nyeri menstruasi digunakan sebagai variabel dependen. Data yang didapat akan dianalisis univariat dan biavariat.

\section{Rancangan Penelitian}

Berikut ini gambar 1 kerangka kerja penelitian yang di lakukan dari penentuan sampel, penetapan variabel penelitian, pengumpulan data, pengolahan data, analisis data sampai penarikan kesimpulan.

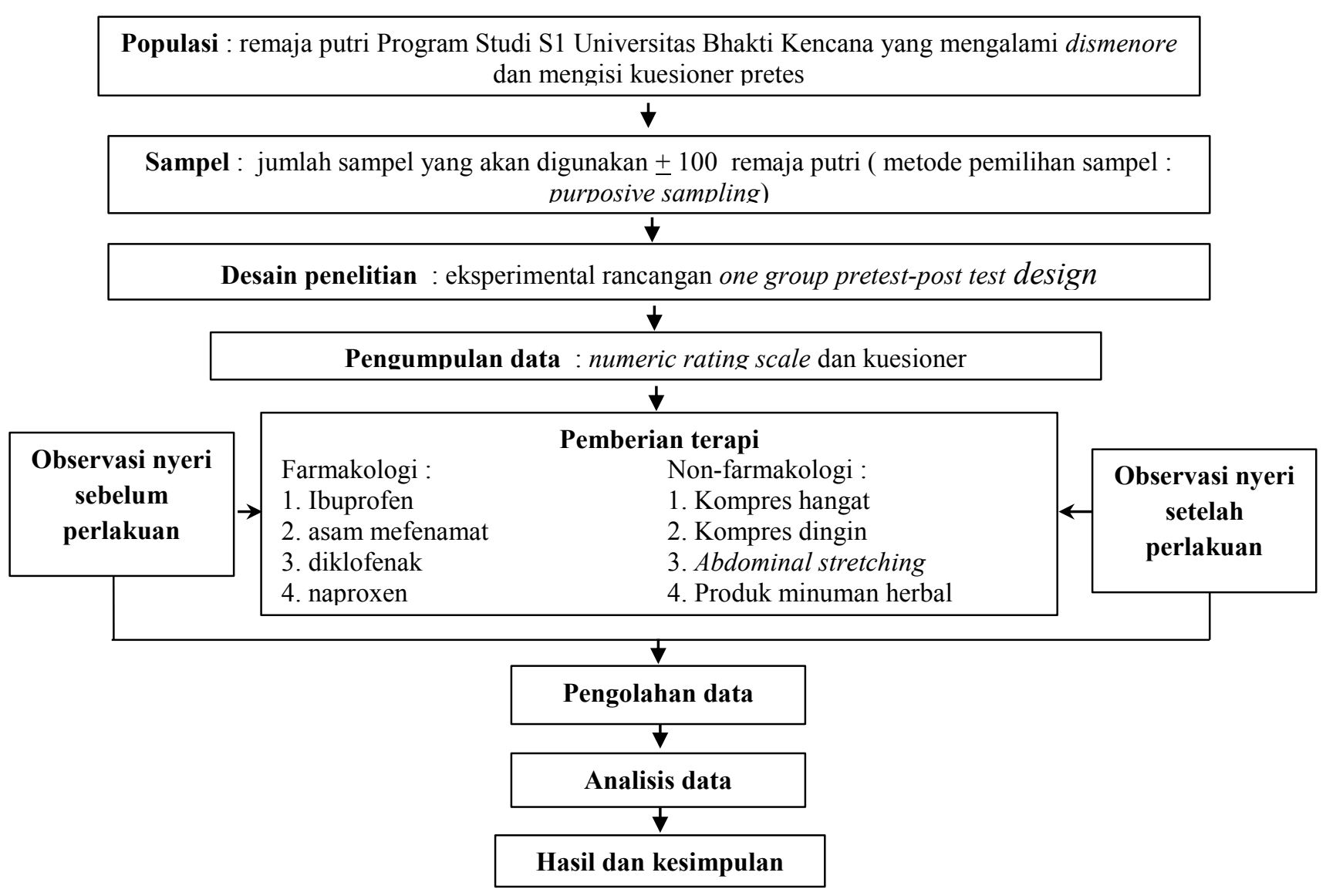


Gambar 1. Rancangan Penelitian

\section{HASIL DAN PEMBAHASAN}

Hasil penelitian meliputi : intensitas nyeri menstruasi pada saat sebelum melakukan terapi dan sesudah terapi dan pengaruh terapi terhadap intensitas nyeri menstruasi pada mahasiswi.

Tabel 1. Karakteristik Responden Berdasarkan Gejala Lain Yang Timbul Saat Nyeri Menstruasi Sebelum Terapi (PRETES)

\begin{tabular}{|c|c|c|}
\hline Nyeri menstruasi disertai sakit pinggang & Jumlah & Persentase \\
\hline Selalu & 30 & $39 \%$ \\
\hline Terkadang & 46 & $61 \%$ \\
\hline Tidak pernah & 0 & $0 \%$ \\
\hline Jumlah & 76 & $100 \%$ \\
\hline \multicolumn{3}{|l|}{ Nyeri menstruasi disertai pegal-pegal } \\
\hline Selalu & 39 & $51 \%$ \\
\hline Terkadang & 37 & $49 \%$ \\
\hline Tidak pernah & 0 & $0 \%$ \\
\hline Jumlah & 76 & $100 \%$ \\
\hline \multicolumn{3}{|l|}{ Nyeri menstruasi disertai perut kembung } \\
\hline Selalu & 8 & $11 \%$ \\
\hline Terkadang & 38 & $50 \%$ \\
\hline Tidak pernah & 30 & $39 \%$ \\
\hline Jumlah & 76 & $100 \%$ \\
\hline \multicolumn{3}{|l|}{ Nyeri menstruasi disertai rasa lelah } \\
\hline Selalu & 22 & $9 \%$ \\
\hline Terkadang & 46 & $61 \%$ \\
\hline Tidak pernah & 8 & $11 \%$ \\
\hline Jumlah & 76 & $100 \%$ \\
\hline \multicolumn{3}{|c|}{ Nyeri menstruasi disertai detak jantung yang berdebar-debar } \\
\hline Selalu & 0 & $0 \%$ \\
\hline Terkadang & 17 & $22 \%$ \\
\hline Tidak pernah & 59 & $78 \%$ \\
\hline Jumlah & 76 & $100 \%$ \\
\hline \multicolumn{3}{|l|}{ Nyeri menstruasi disertai nyeri payudara } \\
\hline Selalu & 23 & $30 \%$ \\
\hline Terkadang & 39 & $51 \%$ \\
\hline Tidak pernah & 14 & $18 \%$ \\
\hline Jumlah & 76 & $100 \%$ \\
\hline \multicolumn{3}{|c|}{ Nyeri menstruasi mengganggu aktivitas sehari-hari } \\
\hline Selalu & 11 & $14 \%$ \\
\hline Terkadang & 55 & $72 \%$ \\
\hline Tidak pernah & 10 & $13 \%$ \\
\hline Jumlah & 76 & $100 \%$ \\
\hline
\end{tabular}


Tabel 1 merupakan tabel karakteristik responden berdasarkan gejala lain yang timbul saat nyeri menstruasi dismenore disertai perut kembung. Nyeri menstruasi atau dismenore memiliki dua kategori, yaitu dismenore primer yaitu mengalami nyeri ringan sampai sedang di bagian bawah pusar, diikuti dengan rasa sakit di bagian punggung, pinggang, paha dan kepala sedangkan dismenore sekunder yaitu menyebabkan nyeri yang dapat diketahui dalam 7-8 jam saat proses menstruasi ( (Widowati et al.,2020)

Tabel 2. Karakteristik Responden Berdasarkan Gejala Lain Yang Timbul Saat Nyeri Menstruasi Setelah Terapi (POSTTES)

\begin{tabular}{|c|c|c|}
\hline Nyeri menstruasi disertai sakit pinggang & Jumlah & Persentase \\
\hline Selalu & 0 & $0 \%$ \\
\hline Terkadang & 25 & $33 \%$ \\
\hline Tidak pernah & 51 & $67 \%$ \\
\hline Jumlah & 76 & $100 \%$ \\
\hline \multicolumn{3}{|l|}{ Nyeri menstruasi disertai pegal-pegal } \\
\hline Selalu & 0 & $0 \%$ \\
\hline Terkadang & 25 & $33 \%$ \\
\hline Tidak pernah & 51 & $67 \%$ \\
\hline Jumlah & 76 & $100 \%$ \\
\hline \multicolumn{3}{|l|}{ Nyeri menstruasi disertai perut kembung } \\
\hline Selalu & 0 & $0 \%$ \\
\hline Terkadang & 10 & $13 \%$ \\
\hline Tidak pernah & 66 & $87 \%$ \\
\hline Jumlah & 76 & $100 \%$ \\
\hline \multicolumn{3}{|l|}{ Nyeri menstruasi disertai rasa lelah } \\
\hline Selalu & 0 & $0 \%$ \\
\hline Terkadang & 17 & $22 \%$ \\
\hline Tidak pernah & 59 & $78 \%$ \\
\hline Jumlah & 76 & $100 \%$ \\
\hline \multicolumn{3}{|c|}{ Nyeri menstruasi disertai detak jantung yang berdebar-debar } \\
\hline Selalu & 0 & $0 \%$ \\
\hline Terkadang & 7 & $9 \%$ \\
\hline Tidak pernah & 69 & $91 \%$ \\
\hline Jumlah & 76 & $100 \%$ \\
\hline \multicolumn{3}{|l|}{ Nyeri menstruasi disertai nyeri payudara } \\
\hline Selalu & 0 & $0 \%$ \\
\hline Terkadang & 32 & $42 \%$ \\
\hline Tidak pernah & 44 & $58 \%$ \\
\hline Jumlah & 76 & $100 \%$ \\
\hline \multicolumn{3}{|c|}{ Nyeri menstruasi mengganggu aktivitas sehari-hari } \\
\hline Selalu & 0 & $0 \%$ \\
\hline Terkadang & 12 & $16 \%$ \\
\hline Tidak pernah & 64 & $84 \%$ \\
\hline Jumlah & 76 & $100 \%$ \\
\hline
\end{tabular}


Tabel 2 merupakan tabel karakteristik responden berdasarkan gejala lain yang muncul saat nyeri menstruasi sesudah melakukan terapi. Data tersebut didapatkan dari hasil kuesioner postes setelah pemberian terapi. Setelah melihat data tersebut, diketahui bahwa gejalagejala yang dirasakan mengalami penurunan rasa nyeri. Sebanyak 67\% responden tidak lagi merasakan nyeri menstruasi disertai sakit pinggang dan pegal-pegal. $87 \%$ responden juga tidak lagi merasakan nyeri menstruasi disertai perut kembung. Nyeri menstruasi disertai rasa lelah tidak lagi dirasakan oleh 78\% responden. Sebagian besar responden atau sebanyak $91 \%$ responden juga tidak lagi merasakan nyeri menstruasi disertai detak jantung yang berdebar-debar setelah melakukan terapi. Nyeri menstruasi disertai nyeri payudara tidak lagi dirasakan oleh 58\% responden setelah melakukan terapi. Dan sebanyak $84 \%$ responden yang mengalami nyeri menstruasi dapat melakukan aktivitas seperti biasa setelah melakukan terapi. Salah satu upaya untuk mengatasi nyeri menstruasi ialah dengan terapi non-farmakologi dengan kompres hangat, kompres dingin, peregangan perut, dan konsumsi jamu/produk minuman herbal. Untuk terapi farmakologi dapat dilakukan dengan mengkonsumsi obat analgesik golongan OAINS. OAINS bekerja dengan cara menghambat produksi prostaglandin yang dapat menyebabkan nyeri saat menstruasi. $85 \%$ obat-obat golongan OAINS terbukti manjur untuk mengatasi nyeri menstruasi (Ayu et al., 2015).

Tabel 3. Karakteristik Responden Berdasarkan Terapi Non Farmaskologi dan Farmakologi

\begin{tabular}{lcc}
\hline \multicolumn{1}{c}{ Upaya terapi yang dilakukan } & Jumlah & Persentase \\
\hline Terapi Non Farmakologi & & \\
Kompres hangat & 38 & $50 \%$ \\
Kompres dingin & 3 & $4 \%$ \\
Abdominal stretching & 7 & $9 \%$ \\
Konsumsi jamu/minuman herbal & 5 & $7 \%$ \\
Terapi Farmakologi & & \\
Diklofenak & 1 & $1 \%$ \\
Ibuprofen & 13 & $17 \%$
\end{tabular}




\begin{tabular}{|c|c|c|}
\hline Asam mefenamat & 9 & $12 \%$ \\
\hline Naproxen & 0 & $0 \%$ \\
\hline Jumlah & 76 & $100 \%$ \\
\hline
\end{tabular}

Berdasarkan hasil pengisian kuesioner oleh responden, dapat diketahui dari 76 responden sebanyak $50 \%$ responden memilih terapi non-farmakologi dengan melakukan kompres hangat untuk mengatasi nyeri menstruasi yang dirasakan. Sebanyak 4\% responden melakukan kompres dingin, sebanyak 9\% responden melakukan abdominal stretching, $\quad 7 \% \quad$ responden mengkonsumsi jamu/minuman herbal untuk mengatasi nyeri menstruasi dan sisanya $23 \%$ tidak melakukan terapi nonfarmakologi atau melakukan terapi farmakologi. Mayoritas responden lebih memilih terapi non-farmakologi dengan kompres hangat karena terapi tersebut mudah dilakukan dan tidak menimbulkan efek samping. Selain itu, kompres hangat memiliki efek terapi yang berguna mengurangi rasa nyeri menstruasi diantaranya yaitu, meningkatkan permeabel kapiler yang menyebabkan peningkatan aliran darah dan mengurangi ketegangan otot perut, sehingga relaksasi otot meningkat dan kekakuan karena nyeri menstruasi dapat berkurang (Misliani et al., 2019).
Kompres hangat dapat dilakukan dengan menggunakan buli-buli pengompres air hangat atau dengan botol kaca diisi dengan air panas $\left(44^{\circ} \mathrm{C}\right)$ dan dibungkus menggunakan kain. Kompres hangat yang dilakukan pada bagian bawah perut menghasilkan panas yang menyebabkan pelebaran pembuluh darah juga menurunannya ketegangan otot perut, akibatnya nyeri menstruasi dapat berkurang (Eka Yuli Handayani, 2018). Pada kompres dingin, rasa dingin sebagai peralihan dari rasa nyeri, maka rasa dingin jadi lebih dominan membuat perasaan lebih nyaman dari pada rasa sakit akibat nyeri menstruasi (Maimunah et al., 017).

Abdominal stretching merupakan latihan fisik ringan untuk meregangkan otot perut yang dilakukan selama 10-15 manit. Gerakan Abdominal stretching dapat meningkatkan aliran darah juga merangsang hormon endorphin yang dapat menurunkan intensitas nyeri menstruasi. Selain itu, meningkatkan kekuatan otot dan fleksibilitas otot perut merupakan tujuan dari gerakan abdominal stretching sehingga dapat mengurangi nyeri menstruasi yang https://doi.org/10.33759/jrki.v3i3.156 
dirasakan oleh remaja putri (Hidayah et al., 2017). Penanganan non-farmakologi lainnya yang sering digunakan yaitu dengan mengkonsumsi jamu-jamuan atau produk minuman herbal. Produk herbal menjadi pilihan untuk mengurangi rasa nyeri akibat menstruasi tanpa merasakan efek samping. Salah satu produk herbal yang banyak digunakan oleh remaja putri yaitu minuman yang mengandung kunyit. Alaminya di dalam kunyit terkandung bahan aktif sebagai pereda nyeri, penurun demam dan anti radang. Produk herbal yang mengandung kunyit dapat digunakan sebagai pengurang rasa nyeri akibat menstruasi dengan efek samping yang minimal (Widowati et al.,2020).

Dapat diketahui bahwa sebanyak 1\% responden memilih terapi farmakologi dengan mengkonsumsi diklofenak, 17\% mengkonsumsi ibuprofen, $\quad 1 \%$ mengkonsumsi asam mefenamat untuk mengurangi rasa nyeri menstruasi yang dirasakan dan sebanyak 70\% tidak melakukan terapi farmakologi. Mengingat peran prostaglandin dalam etiologi nyeri menstruasi, OAINS merupakan pilihan awal dalam terapi farmakologi. Obat golongan OAINS yang sering digunakan adalah ibuprofen dan asam mefenamat. OAINS dipilih karena bekerja menghambat produksi prostaglandin. Dengan menghambat produksi prostaglandin, dapat menurunkan rasa nyeri dan menurunkan kontraksi uterus. Terapi farmakologi dengan menggunakan obat-obatan sesuai dengan penelitian yang dilakukan oleh (Misliani et al., 2019) bahwa untuk mengatasi nyeri menstruasi membutuhkan obat penghilang rasa nyeri sehingga remaja putri yang merasakan nyeri menstruasi masih dapat melakukan kegiatan sehari-hari

Tabel 4. Karakteristik Responden Berdasarkan Intensitas Nyeri Yang Dirasakan Oleh Responden

\begin{tabular}{|c|c|c|c|c|}
\hline \multirow{2}{*}{ Intensitas nyeri yang dirasakan } & \multicolumn{2}{|c|}{ Sebelum terapi } & \multicolumn{2}{|c|}{ Sesudah terapi } \\
\hline & Jumlah & Persentase & Jumlah & Persentase \\
\hline Tidak nyeri & 0 & $0 \%$ & 49 & $64 \%$ \\
\hline Nyeri ringan & 0 & $0 \%$ & 27 & $36 \%$ \\
\hline Nyeri sedang & 37 & $49 \%$ & 0 & $0 \%$ \\
\hline Nyeri berat terkontrol & 39 & $51 \%$ & 0 & $0 \%$ \\
\hline Nyeri berat tidak terkontrol & 0 & $0 \%$ & 0 & $0 \%$ \\
\hline Jumlah & 76 & $100 \%$ & 76 & $100 \%$ \\
\hline
\end{tabular}


Tabel 4 merupakan tabel karakteristik responden berdasarkan intensitas nyeri menstruasi yang dirasakan oleh responden pada saat sebelum terapi dan sesudah terapi. Berdasarkan tabel tersebut, dapat dilihat bahwa sebelum melakukan terapi terdapat $49 \%$ responden mengalami nyeri sedang dan sebanyak $51 \%$ responden mengalami nyeri berat terkontrol. Setelah melakukan terapi, 64\% responden tidak lagi merasakan nyeri menstruasi dan sebanyak $36 \%$ responden mengalami penurunan intensitas menjadi nyeri ringan setelah melakukan terapi.

Responden mengukur intensitas nyeri menstruasi yang dirasakan menggunakan Pain Assesment Tool yang dicantumkan dalam kuesioner pretas dan postes. Intensitas nyeri menstruasi dideskripsikan melalui ekspresi saat mengalami nyeri menstruasi. Terdapat lima tingkat nyeri yaitu, 0 untuk wajah bahagia, karena responden tidak merasakan nyeri menstruasi. 1-3 untuk wajah nyeri ringan, responden yang merasakan nyeri menstruasi ringan belum memilih terapi untuk mengatasi nyeri menstruasi hanya memerlukan istirahat sejenak dan masih dapat beraktivitas dengan baik. 4-6 untuk wajah sedikit sedih karena responden yang merasakan nyeri menstruasi sedang, responden mulai memerlukan istirahat yang cukup. Selanjutnya 7-9 untuk wajah sedih, karena responden yang merasakan nyeri menstruasi berat terkontrol, responden juga merasakan gejala lain yang muncul saat menstruasi, seperti nyeri pinggang, pegal-pegal, nyeri payudara hingga merasa lelah. Responden mulai melakukan pengobatan, minimal terapi nonfarmakologi untuk mengatasi nyeri menstruasi yang dirasakan agar tidak terjadi hal yang lebih berbahaya. Yang terakhir yaitu 10 untuk wajah sedih sampai keluar air mata, walaupun keadaan aslinya tidak sampai mengeluarkan air mata saat merasakan nyeri berat yang tidak terkontrol ini. Pada nyeri menstruasi berat tidak terkontrol, nyeri yang dirasakan lebih meningkat sehingga diperlukan istirahat total hingga meninggalkan aktivitas sehari-hari (Hidayah et al., 2017).

Tabel 5. Analisis Pengaruh Sebelum Melakukan Terapi Dan Sesudah Melakukan Terapi 


\begin{tabular}{r}
\hline Test $_{\text {Statistics }}{ }^{\mathbf{a}}$ \\
Nyeri sebelum - nyeri setelah
\end{tabular}

Tabel 5 merupakan tabel Uji Wilcoxon, menghasilkan nilai signifikansi $0,000<$ 0.05, artinya $\mathrm{H}_{0}$ ditolak dan $\mathrm{H}_{\mathrm{a}}$ diterima. Artinya terdapat perbedaan intensitas nyeri menstruasi yang dirasakan responden saat sebelum terapi dan sesudah pemberian terapi. Maka dapat diambil kesimpulan bahwa terdapat pengaruh terapi farmakologi dan nonfarmakologi terhadap penurunan intensitas nyeri menstruasi pada mahasiswi di Universitas Bhakti Kencana Bandung Fakultas Farmasi.

Tabel 6. Analisis Pengaruh Terapi Non-Farmakologi Terhadap Penurunan Intensitas Nyeri Menstruasi

\begin{tabular}{lr}
\hline \multicolumn{2}{c}{ Chi-Square Tests } \\
\hline \multicolumn{2}{c}{ Asymp. Sig. (2-sided) } \\
Pearson Chi-Square &, 514 \\
\hline
\end{tabular}

Tabel 6 merupakan tabel Uji Chi-Square Test, yang menghasilkan signifikansi $0,514>0,05$, artinya $\mathrm{H}_{0}$ diterima. Artinya, tidak ada pengaruh yang signifikan antara terapi non-farmakologi terhadap intensitas nyeri menstruasi pada mahasiswi. Tujuan terapi nonfarmakologi hanya untuk mengurangi rasa nyeri menstruasi yang dialami. Upaya terapi non-farmakologi merangsang produksi endorfin yang memblok neuron sensorik sebagai substansi terjadinya rasa nyeri, sehingga impuls nyeri ke lobus parietal dihambat dan dapat mengurangi rasa nyeri (Kusmiyati, 2018).

Tabel 7 Analisis Pengaruh Terapi Farmakologi Terhadap Penurunan Intensitas Nyeri Menstruasi

$\frac{\text { Chi-Square Tests }}{\text { Asymp. Sig. (2-sided) }}$


Tabel 7 merupakan tabel Uji Chi-Square Test menggunakan program SPSS, dengan hasil Asymp. Sig. 0,019<0,05, artinya $\mathrm{H}_{0}$ ditolak. Berarti ada hubungan yang signifikan antara terapi farmakologi terhadap intensitas nyeri menstruasi pada mahasiswi. Terapi farmakologi untuk mengatasi nyeri menstruasi yang paling efektif adalah dengan penggunaan obat analgesik golongan OAINS. Analgesik dapat dikatakan efektif untuk menghilangkan rasa nyeri karena bekerja dengan cara menghalangi mediator sehingga aktifitas enzim siklooksigenase terhambat dan pembentukan prostaglandin tidak terjadi (Kusmiyati, 2018).

Obat anti-inflamasi nonsteroid OAINS atau Nonsteroidal anti-inflammatory drugs NSAIDs ialah zat kimia/obat yang dapat memberikan efek analgesik pereda nyeri dan antipiretik penurun panas, dan pada dosis tinggi dapat memberikan efek anti-inflamasi. OAINS bekerja dengan cara menghambat produksi prostaglandin yang dapat menyebabkan nyeri saat menstruasi. $\pm 85 \%$ obat-obat golongan OAINS terbukti manjur untuk mengatasi disminore primer (Ayu et al., 2015).

\section{KESIMPULAN}

Berdasarkan hasil analisis data, dapat disimpulkan bahwa :

1. Intensitas nyeri menstruasi yang dirasakan oleh mahasiswi di Universitas Bhakti Kencana Bandung sebanyak $51 \%$ mengalami nyeri berat terkontrol.

2. Terdapat pengaruh terapi farmakologi dan nonfarmakologi terhadap penurunan intensitas nyeri menstruasi pada mahasiswi di Universitas Bhakti Kencana Bandung. Setelah melakukan terapi sebanyak $64 \%$ mahasiswi tidak lagi merasakan nyeri menstruasi.

3. Terapi non-farmakologi tidak memiliki pengaruh yang signifikan terhadap penurunan intensitas nyeri menstruasi. Karena, terapi non-farmakologi dapat dikatakan upaya yang dapat dilakukan hanya untuk mengurangi rasa nyeri menstruasi yang dialami.

4. Terapi farmakologi memiliki pengaruh yang signifikan terhadap penurunan intensitas nyeri menstruasi. Terapi farmakologi dapat dikatakan 


$\begin{array}{lrr}\text { efektif, karena } & \text { dengan } \\ \text { penggunaan obat analgesik } \\ \text { golongan OAINS } & \text { dapat } \\ \text { menghilangkan rasa } & \text { nyeri } \\ \text { menstruasi. } & & \end{array}$

\section{UCAPAN TERIMAKASIH}

Pada kesempatan ini, peneliti ingin mengucapkan terima kasih kepada berbagai pihak yang telah membantu terwujudnya penelitian ini :

1. Rektor Universitas Bhakti Kencana

2. Ketua Lembaga Penelitian dan Pengabdian Universitas Bhakti Kencana

\section{DAFTAR PUSTAKA}

Asmita dahlan, T.V.S., 2016. PENGARUH TERAPI KOMPRES HANGAT TERHADAP NYERI HAID ( DISMENOREA ) PADA SISWI SMK PERBANKAN SIMPANG HARU PADANG Asmita dahlan , Tri Veni Syahminan PENDAHULUAN Masa remaja adalah masa peralihan dari anak-anak ke dewasa, bukan hanya dalam arti psikologis ,. J. IPTEKS Terap. Res. Appl. Sci. Educ. V10.i2 ISSN 2, 141-147. Ayu, M.R., Alioes, Y., Rahmatini, R., 186
2015. Hubungan Derajat Nyeri

Dismenorea terhadap Penggunaan

Obat Anti Inflamasi Non Steroid.

J. Kesehat. Andalas 4, 551-555.

https://doi.org/10.25077/jka.v4i2.2 98

Chisholm-Burns, M.A.,

Schwinghammer, T.L., Wells, B.G., Malone, P.M., Kolesar, J.M., Dipiro, J.T., 2017. FOURTH EDITION :

PHARMACOTHERAPY PRINCIPLES \& PRACTICE.

Dipiro, J.T., Talbert, R.L., Yee, G.C., Matzke, G.R., Wells, B.G., Posey, L.M., 2017. Chapter e1: Health Literacy and Medication Use 10 edition, 1-6513.

Eka Yuli Handayani, A. syahadat, 2018. PENCEGAHAN NYERI HAID MELALUI PEMANFAATAN TERAPI NON-FARMAKOLOGI PADA REMAJA PUTRI SMAN I

TAMBUSAI dilakukan banyak remaja putri yang farmakologis dalam mengurangi nyeri tertarik untuk melakukan penelitian tentang pencegahan nyeri haid dengan 2, 14-20.

Fitri Maulani, M., Wulandari, P., Kustriyani Program Studi Ners https://doi.org/10.33759/jrki.v3i3.156 
STIKES Widya Husada Semarang, M., Subali Raya No, J., -Semarang, K., 2018. Pengaruh Rebusan Daun Pepaya Terhadap Intensitas Nyeri Haid Pada Siswi Sltp. J. Ners Widya Husada 5, 79-86.

Hidayah, N., Rusnoto, Fatma, I., 2017.

PENGARUH ABDOMINAL STRETCHING EXERCISE

TERHADAP PENURUNAN

DISMENORE PADA SISWI

REMAJA DI

MADRASAHALIYAH HASYIM

ASY'ARI BANGSRI

KABUPATEN JEPARA 954-963.

Karunia, N.R., Peni, T., Virda, E., 2018.

Novia Rina Karunia Program Studi

Ilmu Keperawatan.

Kusmiyati, 2018. NYERI HAID,

PENYEBAB, DAN

PENANGGULANGANNYA VI, $367-372$.

Lestari, R.T.R., Made, N., Wati, N.,

Juanamasta, I.G., Luh, N.,

Thrisnadewi, P., Kunci, K., 2019.

Pengaruh Terapi Yoga (

Paschimottanasana dan Adho

Mukha Padmasana ) terhadap

Intensitas Nyeri pada Remaja Putri

yang Mengalami Dismenore

Primer The Effect of Yoga
Therapy ( Paschimottanasana and Adho Mukha Padmasana ) on Pain Intensity in Adolescence Girl. J. Heal. Sci. Prev. 3, 95-97.

Maimunah, S., Sari, R.D.P., Prabowo, A.Y., 2017. Perbandingan Efektivitas Kompres Hangat dan Kompres Dingin sebagai Terapi Non-Farmakologis Dismenore pada Remaja. Medula 7, 79-83.

Misliani, A., Mahdalena, Syamsul, F., 2019. Penanganan Dismenore Cara Farmakologi dan Nonfarmakologi.

J. Citra Keperawatan 7, 23-32.

Novita, R., 2018. Hubungan Status Gizi dengan Gangguan Menstruasi pada Remaja Putri di SMA Al-Azhar Surabaya Correlation between Nutritional Status and Menstrual Disorders of Female Adolescent in SMA Al-Azhar Surabaya 172-181. https://doi.org/10.20473/amnt.v2.i 2.2018.172-181

Rahmawati, E., 2016. Pengaruh teknik relaksasi progresif terhadap tingkat nyeri haid (dismenorhea) pada mahasiswi di universitas 'aisyiyah yogyakarta.

Sujarweni, W. V., Utami, L.R., 2019. The Master Book of SPSS, Anak https://doi.org/10.33759/jrki.v3i3.156 
Hebat Indonesia.

Umi Latifah Fahmi, Farid Agushybana,

S.W., 2018. FAKTOR-FAKTOR

YANG HUBUNGAN DENGAN

GANGGUAN MENSTRUASI

PADA COMMUTER

(PENGLAJU) Studi Kasus di

Kecamatan Karangawen

Kabupaten Demak Tahun 2018 6, 230-240.

Wahyuni, L.T., 2018. Pengaruh

Konsumsi Coklat Hitam Terhadap
Penurunan Tingkat Nyeri Haid

(Dismenor Primer) Pada

Mahasiswi Ilmu Keperawatan

STIKES Ranah Minang Padang.

Menara Ilmu 12, 73-78.

Widowati, Retno. Kundaryati, Rini.

Ernawati, N., 2020. Pengaruh

Pemberian Minuman Madu Kunyit

Terhadap Tingkat Nyeri

Menstruasi. J. Ilmu dan Budaya

Vol. 41, 7809-7824. 